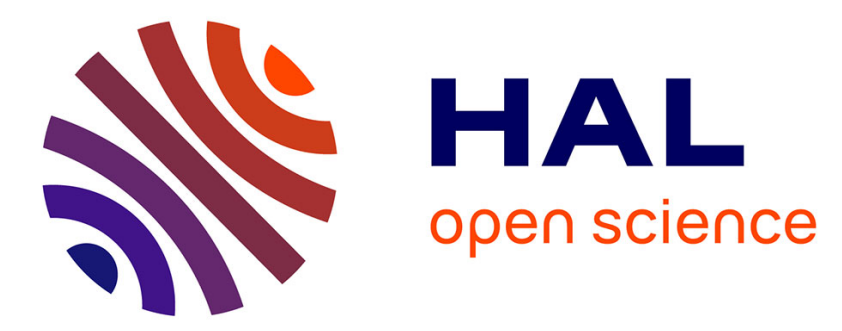

\title{
Securing Victory or Not? Surrendering Optimal Play when Facing Simple Calculations -A Natural Experiment from the Swedish and US Jeopardy
} Jenny Charlotta Säve-Söderbergh, Gabriella Sjögren Lindquist

\section{- To cite this version:}

Jenny Charlotta Säve-Söderbergh, Gabriella Sjögren Lindquist. Securing Victory or Not? Surrendering Optimal Play when Facing Simple Calculations -A Natural Experiment from the Swedish and US Jeopardy. Applied Economics, 2011, pp.1. 10.1080/00036846.2010.522525 . hal-00675398

\section{HAL Id: hal-00675398 https://hal.science/hal-00675398}

Submitted on 1 Mar 2012

HAL is a multi-disciplinary open access archive for the deposit and dissemination of scientific research documents, whether they are published or not. The documents may come from teaching and research institutions in France or abroad, or from public or private research centers.
L'archive ouverte pluridisciplinaire HAL, est destinée au dépôt et à la diffusion de documents scientifiques de niveau recherche, publiés ou non, émanant des établissements d'enseignement et de recherche français ou étrangers, des laboratoires publics ou privés. 


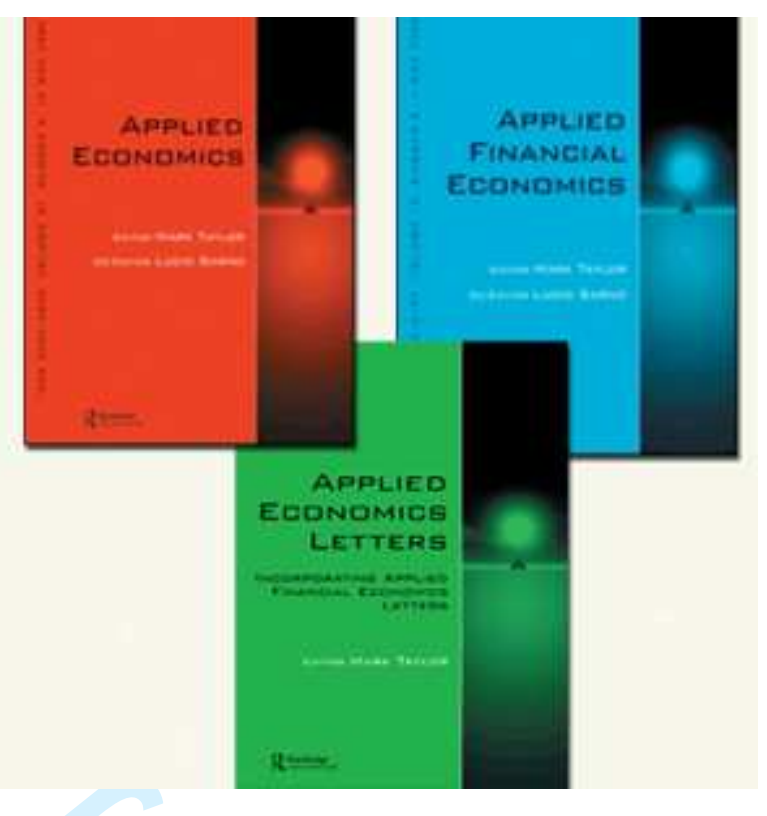

\section{Securing Victory or Not? \\ Surrendering Optimal Play when Facing Simple Calculations -A Natural Experiment from the Swedish and US Jeopardy}

\begin{tabular}{|r|l|}
\hline Journal: & Applied Economics \\
\hline Manuscript ID: & APE-2009-0268.R1 \\
\hline Journal Selection: & Applied Economics \\
\hline Date Submitted by the \\
Author: & 11 -Nov-2009 \\
\hline Complete List of Authors: & $\begin{array}{l}\text { Säve-Söderbergh, Jenny; The Swedish Institute for Social } \\
\text { Research, Stockholm university } \\
\text { Sjögren Lindquist, Gabriella; Swedish Institute for Social Research, } \\
\text { Stockholm University }\end{array}$ \\
\hline JEL Code: & $\begin{array}{l}\text { D81 - Criteria for Decision-Making under Risk and Uncertainty < D8 } \\
\text { - Information and Uncertainty < D - Microeconomics, C93 - Field } \\
\text { Quantitative Methods, C72 - Noncooperative Games < C7 - Game } \\
\text { Theory and Bargaining Theory < C - Mathematical and Quantitative } \\
\text { Methods }\end{array}$ \\
\hline Keywords: & $\begin{array}{l}\text { Individual Decision-making, Bounded Rationality, Natural } \\
\text { Experiment, Game-Show }\end{array}$ \\
\hline
\end{tabular}




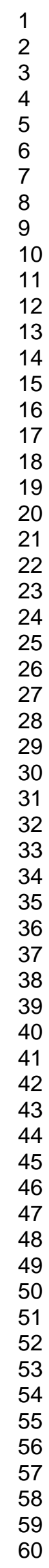

\section{S) ScholaroNE" \\ Manuscript Central}




\title{
Securing Victory or Not? \\ Surrendering Optimal Play when Facing Simple Calculations \\ - A Natural Experiment from the Swedish and U.S. Jeopardy*
}

\author{
Gabriella Sjögren Lindquist \\ Swedish Institute for Social Research, \\ Stockholm University, \\ Universitetsvägen $10 \mathrm{E}$, \\ SE-10691 Stockholm, Sweden \\ email: gabriella.sjogren.lindquist@sofi.su.se \\ Jenny Säve-Söderbergh \\ Swedish Institute for Social Research, \\ Stockholm University, \\ Universitetsvägen $10 \mathrm{E}$, \\ SE-10691 Stockholm, Sweden \\ email: jenny.save-soderbergh@,sofi.su.se \\ tel +46-8-162497, fax: +46-8-154670
}

\begin{abstract}
This paper empirically investigates the common assumption of economic agents' capabilities to process complex mathematical problems to find optimal strategies applied in economic modeling. By exploiting a design difference in the game show Jeopardy between the U.S. and Sweden we obtain a natural experiment of individuals facing an optimization decision either having explicit information or deriving it by non-complex adding and subtracting. Given the assumption that individuals compute optimally, there should be no difference in the strategies used. Yet, the results show that even a small change in informational pre-conditions for obtaining an optimal strategy strongly alters economic-decision making.
\end{abstract}

Keywords: Individual Decision-making, Bounded Rationality, Natural Experiment, Game Show

JEL Codes: C93, C72, D81 


\section{Introduction}

An enduring controversy in economics regards the conflict between the assumption of rationality and the fact that economic agents have limited capacities to process information. Individuals are commonly assumed in theory to be able to compute their optimal strategy for a given situation, regardless of the extent of computational abilities necessary to reach the optimal decision. Such rationality of an agent is often criticized for being too strong an assumption since many maximization problems are quite difficult, which implies that people would not be able to carry them out in practice.

In this paper we explore the assumption that individuals are able to calculate an optimal strategy by taking advantage of a design difference in the game show Jeopardy between the U.S. and Sweden. The vital difference in the design is that in the U.S. game contestants are given explicit information before they act, while in the Swedish version contestants need to perform calculations to possess the same information. Given that individuals are capable of computing optimally, there should be no difference in the strategies used in the two designs. This is especially the case since acquiring the information merely requires tedious but simple addition and subtraction on the part of the player. Consequently, the difference in the design of the otherwise similar games can be used as a natural experiment. On top of that, by using a television game show, we obtain the advantage of a natural large-stake setting for decision making. ${ }^{1}$ In addition, by exploring the design difference of the games, our paper complements earlier research on rationality by using a control and treatment approach in which only one condition is changed the need for individual calculation.

\footnotetext{
${ }^{1}$ The maximum amount a contestant can gain is SEK (Swedish kronor) 283,200 (U.S.\$1 $\approx$ SEK 8) in 1 show and SEK 1,416,000 in 5 subsequent shows. This requires certain strong restrictions on the evolution of the game, however. The highest gain attained from a single show is SEK 88,200 and SEK 179,900 for 5 subsequent shows. The average gain per contestant is SEK 7,151 and the average gain per show is SEK 13,906 for all the Swedish broadcasts (Jeopardy Historia 2003).
} 
In the game show Jeopardy three participants compete in a quiz game for two successive rounds before they enter a final. In the final of the game, the contestants bid any amount of their accumulated score on their ability to answer a final question. This bid is either added to their score with a correct answer to the final question, or subtracted from it with an incorrect answer. The winner of the game is the contestant with the highest total score. It is this final bidding decision that is the focus of this paper.

In this final bidding situation, the contestant who has the lead before the final play, i.e. the pre-final leader, is faced with two fairly straightforward strategies that he (or she) can apply to guarantee a victory. Given that the pre-final leader is assumed to prefer to win, there should be large incentives for the player to use these strategies.

The strategies are first contingent on how much the pre-final leader is ahead of the runnerup and second on the pre-final leader's knowledge of his lead. It is in this second condition that the game design differs between the two countries. In the U.S. version of the game this information, i.e. the scores, is publicly given to the contestant while in the Swedish design it needs to be derived by adding and subtracting the scores of the other contestants' correct and incorrect answers while actively participating in the game. Apart from the information aspect, and the fact that the final score is converted into each countries' currency, the games have the same strategic set-up. ${ }^{2}$ Given this similarity we may rely on the difference displayed in strategies coming from the need for Swedish players to derive the same information that is explicitly given to U.S. players.

\footnotetext{
${ }^{2}$ Note that U.S.\$1 is approximately equal to SEK 7.5, implying that the stakes are higher in the U.S. However, empirical evidence from game-show data shows that the value of the stakes does not affect the probability of players using optimal behavior. For example, Tenorio and Cason (2002) find within the game show The Price is Right that the size of the stakes does not affect the individuals' probability of behaving rationally. Similarly, Healy and Noussair (2004) find no difference when comparing outcomes from The Price is Right with prizes ranging from U.S. $\$ 1,000$ up to U.S. $\$ 60,000$, with a laboratory setting of the same game having prizes ranging from U.S. $\$ 2$ and U.S.\$100. However, some laboratory experiments using other settings have shown that stakes may matter, see for example Kachelmeier and Shehata (1992).
} 
We ultimately compare the betting strategies applied between the two game designs by replicating the analysis performed by Metrick (1995) for the U.S. Jeopardy with a Swedish sample. The Swedish Jeopardy data are gathered from televised broadcasts of the show during 2002. ${ }^{3}$ The U.S. Jeopardy data are directly based on results published by Metrick (1995). The U.S. sample thus serves as our control group with players having explicit information on the other players' scores, to be compared with our treatment group of players who have to compute the same information. Our aim, however, is not to establish any other betting strategy. We only wish to illuminate how a small change in the preconditions for finding an optimal strategy can alter maximization behavior.

In essence, we find no evidence of the same strategic behavior in our games with selfderived information as that found by Metrick with explicitly given information. Only a negligible share of adopted strategies bear similarity to those in the U.S. sample. This result is somewhat unexpected given that these strategies would have secured a victory. Given the degree of difficulty of the average question on Jeopardy and the high level of general knowledge required by the contestant even to be able to enter the game show, it is clearly the case that contestants on Jeopardy possess intellectual abilities above those of contestants on most other television game shows. ${ }^{4}$ It is therefore surprising that such contestants are unable to keep track of the other two participants' scores in the pre-final rounds when all it involves is adding and deducting. Our results thus suggest that even when faced with a relatively simple problem most contestants show limited ability to calculate optimal strategies.

Related papers are, apart from Metrick (1995), those by Bennett and Hickman (1993), Berk et al. (1996), Healy and Noussair (2004) and Tenorio and Cason (2002), who use different

\footnotetext{
${ }^{3}$ The transmissions are Jeopardy shows from the spring of 2002, the summer of 2002 (video-recorded reruns from the fall of 2001) and the fall of 2002.

${ }^{4}$ Prior to participating in the televised game, all the participants perform a test.
} 
sub-competitions of the game show The Price is Right to evaluate the use of optimal strategies. ${ }^{5}$ It is found that players do not behave rationally if the problem is hard to solve, which is interpreted in terms of bounded rationality. Our paper thus complements these findings, but also differs by using a different setting.

The paper is arranged as follows. In Section 2 the game design is explained and strategies are outlined. Section 3 presents the data. The results are given in Section 4, which is followed by a discussion in Section 5. Section 6 offers concluding remarks.

\section{Jeopardy Game Design and Strategies}

The game show Jeopardy works as follows. After two successive rounds, in which the players accumulate scores according to their ability to answer questions ${ }^{6}$ correctly and their ability to signal that they want to answer by pushing a button, the contestants enter the Jeopardy final.

In the final, the three players privately (i.e. hidden from the other players) bid a chosen amount of their pre-final score on a subject area in which an unknown final question will be asked. If a contestant gives the correct answer to the final question, the bid is added to the contestant's pre-final score. If the answer is incorrect, the bid is subtracted from the pre-final score. The contestant with the highest final score becomes the Jeopardy Champion and keeps a sum in the country's currency equivalent to the amount of the score (less tax). The champion is also invited back to play in a subsequent round of Jeopardy to face new contestants. ${ }^{7}$ The

\footnotetext{
${ }^{5}$ There are several other papers that also use TV game shows as field experiments but that test for other behaviors such as risk aversion or discrimination (Antonovics et al. 2005; Beetsma and Schotman 2001; Fullencamp et al. 2003; Gertner 1993; Post et al. 2008).

${ }^{6}$ A special feature of Jeopardy is that the contestants are given the answer to a question and they have to give the correct question to the answer. To avoid confusion, we will use the term correct "answer" to refer to the correct question that they give.

${ }^{7}$ If two (or all three) players tie, both (or all) keep their prize money and are invited back to the next show as Jeopardy Champions.
} 
maximum number of games a winner can play is five successive rounds. ${ }^{8}$ The first and second runners-up receive non-monetary prizes. ${ }^{9}$

In both countries' versions the contestants are told the score levels of the other contestants at the end of the first round. The vital difference between the U.S. and the Swedish design comes from contestants' information on the other contestants' pre-final scores after the second round. In the Swedish game, the contestants have to add and subtract the scores of the other contestants' correct and incorrect answers while they actively participate in the game. Gathering the information is thus possible by simple math, although it may be tedious. U.S. contestants are explicitly and publicly told the exact score of all the players after the second round has been played.

The strategy we employ is to compare betting strategies between the two game designs. We therefore replicate the analysis performed by Metrick using our Swedish sample. By adopting this set-up we can analyze whether players differ in their betting strategy when the need for basic calculations in the decision process is introduced.

For the pre-final leaders in the U.S. Jeopardy, who are explicitly given information on their lead, Metrick derives two best responses depending upon the amount the pre-final leaders are ahead. ${ }^{10}$ The first best response is found in "runaway games", in which the pre-final leaders' can secure a victory through strategic bidding. Since the final bid, $Y_{1}$, cannot exceed the contestant's pre-final score, $X_{1}$, then at certain relative positions a pre-final leader can guarantee a victory. This applies when the pre-final leader has a pre-final score, $X_{1}$, twice as high as the

\footnotetext{
${ }^{8}$ The maximum number can in fact exceed five, if the winner is selected for the Jeopardy Champion contest that takes place every season. The selected contestants are the three players with the highest winning score attained that season. In the data we have one contestant who appears six times.

${ }^{9}$ The values of the non-monetary prizes are approximately the same for both runners-up.

${ }^{10}$ As pointed out by Metrick, the game-theoretical equilibria of the Jeopardy final are very complex. Like Metrick, we make no attempt to test any game-theoretical predictions. We refer the reader to Metrick (1995), where a stylized version of the U.S. Jeopardy can be found.
} 
pre-final score of the runner-up, $X_{2}$. In these runaway games the leader can be certain of winning as long as his bid does not exceed the difference between his own pre-final score and twice the pre-final score of the runner-up, i.e.

$$
Y_{1}<X_{1}-2 X_{2}
$$

here defined as runaway bids.

The second best response is found in "shut-out games", where the pre-final leader can make a bid ensuring a victory if he (or she) gives the correct answer to the final question. In these games, the pre-final leader's score is not high enough to secure a victory but Metrick shows that the pre-final leader has the possibility to make a bid that shuts-out the runner-up with a correct answer. This is the smallest possible bid that ensures a sole victory if he answers correctly, i.e.

$$
Y_{1}=2 X_{2}-X_{1}+1
$$

here defined as a shut-out bid. An example of such a game is when the pre-final leader has 10,000 and the runner-up has 7,000 (and the third player only has 1,000 and can be ignored), whereupon the maximum amount that the runner-up can win is 14,000 . The smallest possible bid the prefinal leader can make to secure a non-tied victory for a correct answer is $4,001 .^{11}$ Note that it is the smallest possible bid that ensures a victory with a correct answer and that bids above this level also guarantee victory but at the cost of losing more if the answer is incorrect.

\section{Data}

In Table I some summary statistics of the Swedish and U.S. games are shown. The Swedish sample comprises 206 shows, but in 11 of the shows the second runner-up had a negative (or 0 )

\footnotetext{
${ }^{11}$ In Metrick's analysis it is shown that the focal bid is to ensure a sole victory, not a tie. Hence we analogously define a shut-out bid as a bid that secures a sole victory.
} 
pre-final score and thus could not play in the final round. Since the 2 remaining players find themselves in a different strategic situation from that of players in a 3-player game, we exclude these 11 shows from our main sample. Altogether, we have 585 observations. The U.S. sample comprises 393 games and 1150 observations.

There are no noteworthy differences in general between the two countries. Swedish prefinal leaders are only slightly more likely to state the correct answer to the final question compared with U.S. players. In Sweden a few more games start with the pre-final leader having a large lead.

\section{Results}

Metrick reports that, in the U.S. version of Jeopardy, none of the 110 pre-final leaders in runaway games made a bid larger than the runaway bid threshold. Of these, 24 made a bid exactly equal to, or U.S.\$1 less than, the runaway bid threshold. That is, all U.S. pre-final leaders who had the opportunity secured their victory by basing their strategies on the precise score level of the runner-up.

In our Swedish sample, 64 of the 196 pre-final leaders had the opportunity to make runaway bids. The frequencies of runaway bids are summarized in Table II. None of the Swedish pre-final leaders made a bid at, or, like U.S. players, SEK 1 less than the runaway bid threshold and only 17 made runaway bids.

The distribution of bid deviations from the runaway bid threshold for pre-final leaders in runaway games is shown in Figure I. At 0, the pre-final leader made a bid exactly at the runaway bid threshold. In the positive range the bid is higher than the runaway bid threshold and in the negative range all the bids are runaway bids. The majority of bids, 73 percent, are in the positive 
range and among these the absolute deviations are high. Note that in the positive range the bid ensures no victory, either with a correct answer or with an incorrect answer. The average deviation from the runaway bid threshold for the Swedish players is SEK 2,584, which is far above 0 . In a one-sided $t$ test, we can also reject that the average deviation is 0 , or negative, at the 1 percent level. ${ }^{12}$ Hence, in our sample, where players had to perform calculations to receive information on which they could form their strategy, only 27 percent secured a victory, while 100 percent did so in Metrick's sample, where the players have explicit, instead of derived, information.

In the games where the pre-final leader's score is not high enough to secure a victory, i.e. in the shut-out games, Metrick finds that the modal bid for pre-final leaders is the shut-out bid and that this is made in over half of the games. Metrick defines this as a focal bid. In our sample of shut-out games, none of the 132 pre-final leaders chose an exact shut-out bid, and 2 percent placed a bid within a negative deviation of SEK 1, accepting a tie. The statistics are given in Table II. In addition, Metrick finds that 85 percent of the shut-out bids in U.S. Jeopardy are played between a perfect shut-out bid and a positive deviation of 1,000. In contrast, 17 percent of the Swedish players made a bid within this interval.

Figure II shows the distribution of deviations from a shut-out bid. As in the runaway bids' distribution, we find that the majority of the players bet more than the shut-out bid and that the absolute deviations from it are large. The average deviation from a shut-out bid found for the

\footnotetext{
${ }^{12}$ If we allow the pre-final leader to make an error of SEK 500 in calculating the runner-up's score due to the need to derive the information on the other players' scores, the percentage who made runaway bids does not increase. Allowing for an error interval of SEK 1,000 we obtain a percentage of 24 . Note that the percentage falls, since the number of individuals who made runaway bids increases by 2 , but the number of individuals with the possibility of making runaway bids increases by 19. Furthermore, analyzing the deviations from runaway bids shown in Figure I, we observe that the distribution is skewed to the right. If we were to believe that players were simply making calculation errors, then the distribution of deviations should be left of 0 with the errors symmetrically distributed around 0 .
} 
Swedish players is SEK 3,218, which is clearly far from 0 . Moreover, as a result of a one-sided $t$ test, we can reject that the average deviation is equal to 0 at the 1 percent level.

\section{Discussion}

In runaway games, the pre-final leader can win with certainty given that he uses the information on the runner-up's score. However, only 26 percent of participants who had the possibility in our sample behaved rationally and made runaway bids compared with 100 percent in the U.S. Jeopardy. In shut-out games, only 2 percent used the modal strategy adopted by 57 percent of the U.S. players.

In this section we discuss whether these deviations from optimal simply reflect that Swedish players are inexperienced. In his paper, Metrick also analyzes the behavior of the runners-up. He finds that the U.S. runners-up bid non-optimally given the optimal play of the U.S. pre-final leaders and that experience is one explanation for the deviance of non-optimal behavior. Moreover, when analyzing The Price is Right, Bennett and Hickman (1993), Berk et al. (1996), Healy and Noussair (2004) and Tenorio and Cason (2002) find that more experienced individuals behave more "rationally", or in line with what would be optimal, than inexperienced players.

To capture such an experience effect we estimate, similar to Metrick, a logit regression on the probability of placing a runaway bid on the number of games attended. For the Swedish prefinal leaders we find no difference between experienced and inexperienced players, as displayed in Table III. A similar regression but on the probability of placing a bid equal to the shut-out bid or larger, defined as a shut-out interval bid, obtains the same conclusion. Note that all these bids secure a victory for a correct answer but have a higher cost to the player in terms of a larger loss 
if the answer is incorrect. We interpret this absence of an experience effect as the players finding the problem too complex to solve even when they become more experienced.

Further, we explore whether runaway bids or shut-out interval bids are used more often by pre-final leaders when the strategies are easier to compute. Metrick finds that runners-up in games where the optimal strategy is more difficult to calculate are less likely to use optimal strategies. The difficulty of calculating a strategy is measured by the score spread between the pre-final leader and the runner-up. It is assumed that in games with a large score spread it is less tedious for the pre-final leader to keep track of the runner-up's score since the pre-final leader has answered most of the questions himself. Thus, in games with a higher score spread, we would see that Swedish pre-final leaders behave more like those in the U.S. In the runaway games there is an additional positive effect on the probability of using runaway bids with a large score spread as the cut-off level of a runaway bid declines with a higher score spread. For the shut-out games, on the other hand, there is a positive effect with a smaller score spread since, if the pre-final leader has a sense of being very close to the runner-up, he knows that to be able to win the game he has to place a higher bid to win with a correct answer.

Similar to Metrick, we construct a variable, RATIO, which is the ratio between $X_{2}$ and $X_{1}$, to capture the score spread between the pre-final leader and the runner-up. As suggested by the estimates displayed in Table III, we find, in line with our hypothesis, a positive significant correlation between the probability of placing a runaway bid and the score spread. ${ }^{13}$ For the shutout interval bids we find the negative effect on the score spread to be dominant. Consequently, we do not argue that players necessarily are totally unable to keep track of each others' scores -

\footnotetext{
${ }^{13}$ If we contemplate that it is easy to compute the score differences, then strategic play ought to be more likely in the games with only two players. In these games the second runner-up performed so badly that the score can be ignored. In our 11 two-player games the probability of using runaway bids is 0 . For the shut-out games the probability of making a shut-out interval bid is 0.11 . Hence even when faced with an easier calculation, players still do not play according to runaway or shut-out strategies.
} 
instead they may have a sense of being far behind or very close - just that they do not base their strategies on the exact score level of the other players.

\section{Concluding Remarks}

By analyzing the strategies adopted in the two otherwise similar games, we obtained a test of whether the need for self-deriving information matters for the decision structure. As the strategies of those based on explicit information cannot be replicated by players who need to self-derive the same information, we can establish that altering the pre-conditions of economic decision making can have a large impact. Therefore, assuming that individuals are equipped with a perfect capacity to calculate optimal strategies in any given situation is not unquestionable in general. Considering the fairly non-complex mathematical skills, mainly addition, required for the Jeopardy game, the assumption of individuals having an almost perfect capacity to calculate seems even more difficult to justify for more complex economic decisions. 


\section{References}

Antonovics, K., Arcidiacono, P., Walsh, R., 2005. Games and Discrimination: Lessons from “The Weakest Link", Journal of Human Resources, vol. 40, 918-947.

Beetsma, R., Schotman, P. C., 2001. Measuring Risk Attitudes in a Natural Experiment: Data from the Television Game Show LINGO, Economic Journal, vol. 111, 821-848.

Bennett, R., Hickman, K., 1993. Rationality and the "Price is Right", Journal of Economic Behavior and Organization, vol. 21, 99-105.

Berk, J., Hughson, E., Vandezande, K., 1996. The Price is Right, but are the Bids? An Investigation of Rational Decision Theory, American Economic Review, vol. 86, 954-970.

Fullenkamp, C., Tenorio, R., Battalio, R., 2003. Assessing Individual Risk Attitudes Using Field Data from Lottery Games, The Review of Economics and Statistics, vol. 85, 218226.

Gertner, R., 1993. Game Shows and Economic Behavior: Risk-Taking on "Card Sharks", Quarterly Journal of Economics, vol. 108, 507-521.

Healy, P., Noussair, C., 2004. Bidding Behavior in the "Price is Right" Game: An Experimental Study, Journal of Economic Behavior and Organization, vol. 54, 231-247.

Jeopardy Historia, 2003. http://tv4.se/spel/fragesporter_Jeopardy_historia.asp.

Kachelmeier, S. J., Shehata, M., 1992. Examining Risk Preferences under High Monetary Incentives: Experimental Evidence from the People's Republic of China, American Economic Review, vol. 82, 1120-1141.

Metrick, A., 1995. A Natural Experiment in “Jeopardy!”, American Economic Review, vol. $85,240-253$.

Post, T., Van den Assem, M. J., Baltussen, G., Thaler, R. H., 2008. Deal or No Deal? Decision Making Under Risk in a Large-Payoff Game Show, American Economic Review, vol. $98,38-71$.

Tenorio R., Cason, T. N., 2002. To Spin or Not to Spin? Natural and Laboratory Experiments from The Price is Right, Economic Journal, vol. 112, 170-195. 


\section{Tables}

Table I Summary Statistics

\begin{tabular}{lcc}
\hline & Swedish sample & U.S. sample \\
\cline { 2 - 3 } Pre-Final Leader Correct & $63 \%$ & $54 \%$ \\
Percentage of Runaway Games & $33 \%$ & $28 \%$ \\
Percentage of Shut-out Games & $67 \%$ & $72 \%$ \\
Total Observations & 585 & 1150 \\
Total Games & 196 & 393 \\
\hline Note: The Swedish sample was collected from video-recorded transmissions of Jeopardy during 2002. \\
The U.S. sample is based on published results in Metrick (1995).
\end{tabular}


Table II Behavior of Pre-final Leaders in Runaway Games and Shut-out Games

\begin{tabular}{lcccc}
\hline \hline RUNAWAY GAMES: $X_{1} \geq 2 X_{2}$ & \multicolumn{2}{c}{ Swedish sample } & \multicolumn{2}{c}{ U.S. sample } \\
\cline { 2 - 5 } & Obs. & Freq. & Obs. & Freq. \\
\hline Mean bid deviation from Runaway bids & $2,584^{* * *}$ & & & \\
Bid $\leq$ Runaway bid threshold & $(4,644.3)$ & & & \\
$Y_{1}<X_{1}-2 X_{2}-1$ & 17 & 0.27 & 86 & 0.78 \\
$Y_{1}=X_{1}-2 X_{2}-1$ & 0 & 0.00 & 20 & 0.18 \\
$Y_{1}=X_{1}-2 X_{2}$ & 0 & 0.00 & 4 & 0.04 \\
Bid $>$ Runaway bid threshold & & & & \\
$Y_{1}>X_{1}-2 X_{2}$ & 47 & 0.73 & 0 & 0.00 \\
Total & 64 & 1.00 & 110 & 1.00 \\
Allowing for a SEK 500 error & & & & \\
$Y_{1} \leq X_{1}-2 X_{2}+500$ & 22 & 0.27 & & \\
$Y_{1}>X_{1}-2 X_{2}+500$ & 59 & 0.73 & & \\
Total & 81 & 1.00 & & \\
Allowing for a SEK 1,000 error & & & & \\
$Y_{1} \leq X_{1}-2 X_{2}+1000$ & 24 & 0.24 & & \\
$Y_{1}>X_{1}-2 X_{2}+1000$ & 76 & 0.76 & & \\
Total & 100 & 1.00 & &
\end{tabular}

SHUT-OUT GAMES: $X_{1} \leq 2 X_{2}$

Mean bid deviation from Shut-out bids

$3,218^{* * *}$

$(3,270.7)$

Bid $<$ Shut-out bid-1

$Y_{1}<2 X_{2}-X_{1}+1-1$

$Y_{1}=2 X_{2}-X_{1}+1-1$ (accepting a tie)

16

2

0.12

0.02

8

0.03

Bid $=$ Shut-out bid

$Y_{1}=2 X_{2}-X_{1}+1$

0

0.00

135

0.48

Bid $>$ Shut-out bid

$2 X_{2}-X_{1}+1<Y_{1} \leq 2 X_{2}-X_{1}+1+100$

1

0.01

40

0.14

$2 X_{2}-X_{1}+1+100<Y_{1} \leq 2 X_{2}-X_{1}+1+1,000$

19

0.14

40

0.14

$Y_{1}>2 X_{2}-X_{1}+1+1,000$

94

0.71

34

0.12

Total

132

1.00

283

1.00

Note: Note that in the Swedish sample there are 196 pre-final leaders in 195 games. In 1 game there is a tie between the first player and the runner-up and hence there are 2 pre-final leaders in this game. Standard deviations are given in parenthesis. 
Table III Logit Regression on the Probabilities of Bidding Runaway Bids or Shut-out Bids or Higher for the Swedish Sample of Pre-final Leaders 


\section{Figures}

Frequency

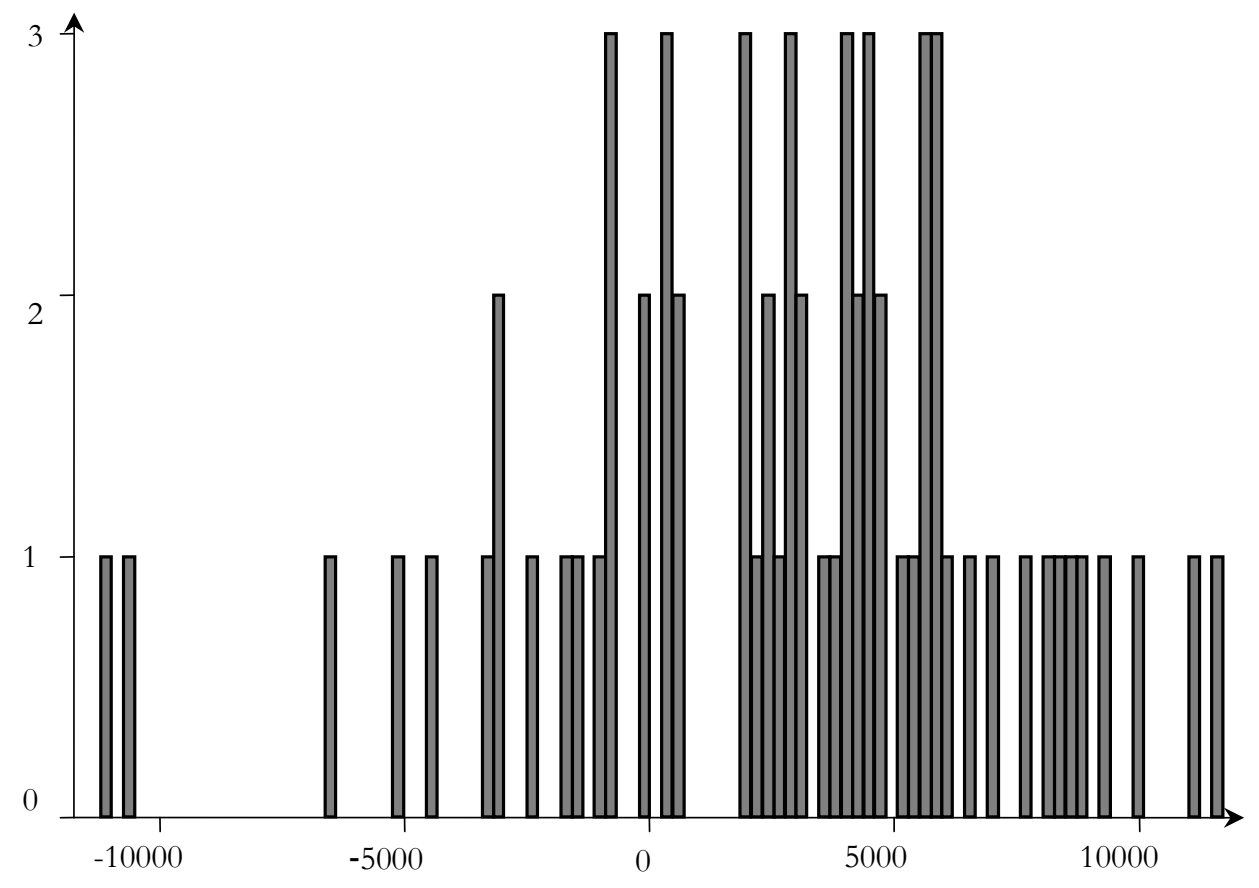

Figure I The Distribution of Bid Deviations from the Runaway Bid Threshold for Pre-final Leaders in Runaway Games 


\section{Frequency}

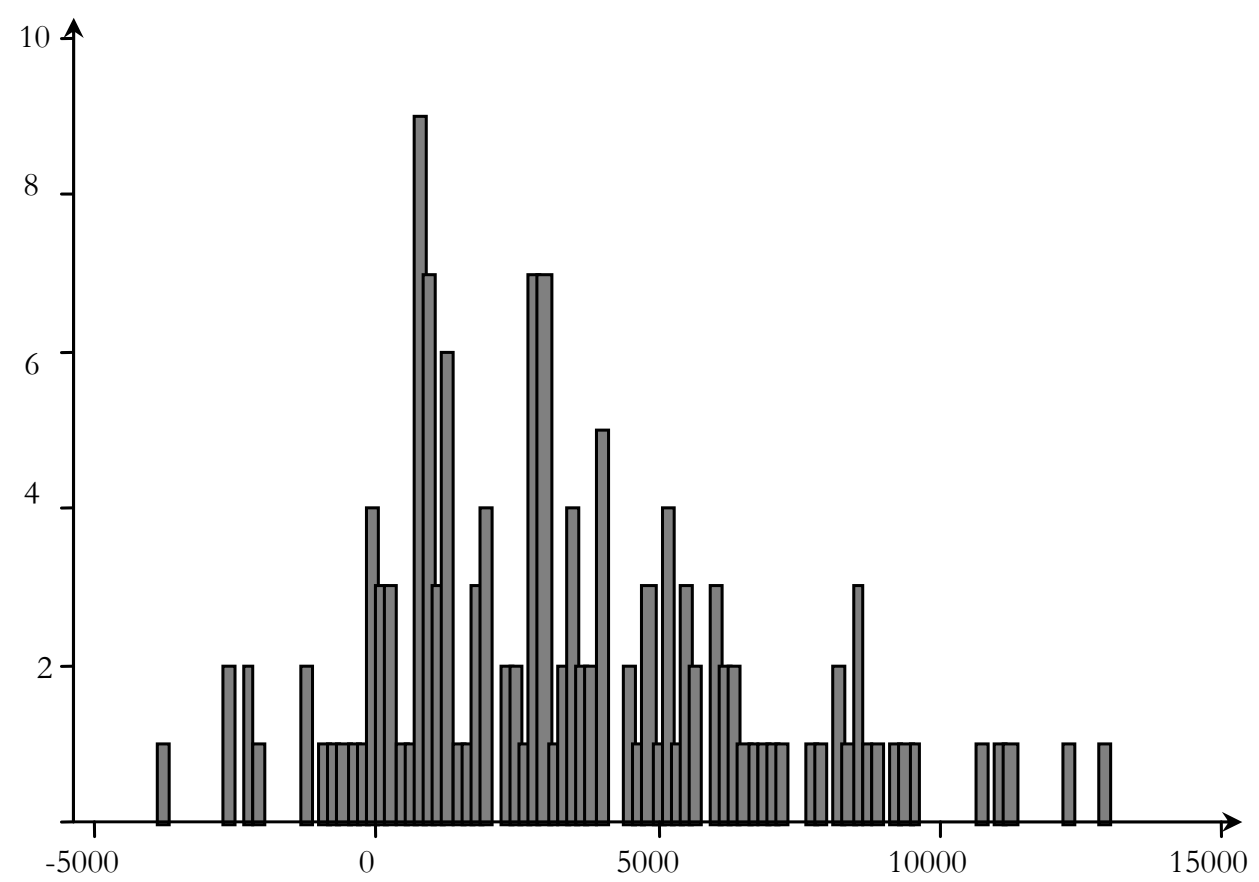

Figure II The Distribution of Bid Deviations from the Shut-out Bid for Pre-final Leaders in Shutout Games

\footnotetext{
* Our special thanks go to Ante Farm, Nabanita Datta Gupta, Martin Dufwenberg, Håkan Holm, Matthew Lindquist, Mikael Priks, Annika Sundén, Eskil Wadensjö and seminar participants at the EALE conference, the Swedish Institute for Social Research, the Department of Economics at Stockholm University and Lund University for valuable comments. The usual disclaimer applies.
} 